with a short section of discussions.

The book contains a large amount of relevant information on the subject matter for those active in the field. As well as this, the layout and presentation are such that there is much to interest the non-specialist.

\section{K. Aitken}

\section{Ganglion Growth Factors}

Nerve Growth Factor and Its Antiserum. Edited by $\mathrm{E}$. Zaimis and $\mathrm{J}$. Knight. (Papers presented at a Symposium held at University College, London, April 1971.) Pp. xi +273. (Athlone: London, June 1972. Distributed by Tiptree Book Services Ltd.)

THIs volume consists of a collection of two dozen papers presented at a symposium held not quite two years ago at University College, London. Its content reflects the excitement, uncertainties, and controversies of a newly and rapidly developing field and points the direction of future research.

Nearly twenty years ago Dr Rita Levi-Montalcini and her associates discovered protein factors which stimulate growth of ganglionic neurones both in vivo and in vitro. The startling effects of antibodies to these proteins on the development of the sympathetic nervous system indicate their physiological importance. During the last ten years other investigators have been stimulated to examine the nature and origin of the protein factors and the biochemical and physiological consequences of administration of the antibodies to these factors.

In the introduction, the editors have succinctly outlined the purposes and objectives of the symposium. The first section is devoted to work which has been done to define the nature and actions of the nerve growth factor, while a second section considers antibodies to NGF, and a brief third section deals with the problems in the assay of NGF and its antibody.

The opening chapters present in adequate detail the methods for purification and characterization of NGF from snake venoms and mouse submaxillary glands. These factors appear clearly different from each other. The well known biological effects of NGF are reviewed by its discoverer and her collaborators along with a report of more recent observations on the subcellular distribution of NGF. The effects of NGF on growth of sympathetic tissues are well illustrated in the paper by Professor Zaimis, after which the biochemical and fine structural chariges induced in sympathetic ganglia in vivo and in vitro are reviewed.

The second section of the volume is concerned with the effects of inhibition by antibodies to NGF of development of the sympathetic nervous system. The consequences of immunosympathectomy on the tissue content and metabolism of amines, and cardiovascular responses and behavioural patterns (by motor activity on exposure to cold) and use of immunosympathectomy as a pharmacological tool, are considered. In the last brief section on assay of NGF and its antibodies, some pitfalls in assays are pointed out and the potential for development of new sensitive radio immunoassays for NGF is indicated.

The various papers are not of uniform detail or quality, but this may reflect the uneven advance of a new field. The editors have not imposed stylistic restrictions on the authors. One feels that a report of discussions of the papers might have enhanced the value of the volume since discrepancies and differences of opinion (for example, the similarities and dissimilarities of NGF from different sources), although recog. nized, pass without comment.

This is a cohesive, well balanced volume which may be considered a milestone marking a point in the development of a new and exciting field. There are wide implications to embryology and plasticity of the nervous system. It should be read by those interested in the problems related to the development of the nervous system as well as investigators concerned with mechanisms of the sympathetic nervous system.

I. J. KOPIN

\section{Pollution by Combustion}

Emissions from Continuous Combus. tion Systems. Edited by W. Cornelius and William G. Agnew. (Proceedings of a Symposium held at the General Motors Research Laboratories, Warren, Michigan, September 1971.) Pp. $x+$ 479. (Plenum: New York and London, 1972.) $\$ 29$.

IT is none too common to be able to read the papers from a serious symposium within a couple of years and so the publishers of these are to be congratulated. The excellent presentation, diagrams, graphs and photographs do much to add to the general worth of this collection of opinions from acknowledged international pundits in the field of combustion. Would-be readers must realize, however, that these papers-and their related edited discussions-require considerable knowledge of thermodynamics, in certain cases fairly advanced mathematics, and some acquaintance with gas turbine and furnace technicalities. Although the ultimate purpose of the symposium was a general review of pollution from these sources and what can be done to reduce it, the speakers dealt with how to do it in the intimate terms of their trades.

General Motors Research Laboratories has held fifteen annual symposia to review the "state of the art" of the various sciences and techniques related to heat engines. The meetings last two days and about sixty delegates are invited after careful selection with a view to bringing together the élite of the academic, industrial and governmental brains concerned with the theme of the year. The choice of the environmental effect of emissions from the combustion of fossil fuels was becoming topical in 1971 and is of paramount importance today.

The symposium was given in four sessions: "Modelling continuous combustion", chaired by J. P. Longwell of Esso Research and Engineering Company; "Pollutant formation and destruction processes", chaired by G. C. Williams of MIT; "Effects of operating conditions and fuel factors", chaired by A. H. Lefebvre of the Cranfield Institute of Technology; and "Powerplant emissions", chaired by P. S. Myers, University of Wisconsin. It would be invidious to name only some of the authors of the twenty-one papers, but the outstandingly clear, concise and objective symposium summary by W. G. Agnew gives a very clear picture of what was said; he also made a profound comment on the general understanding of the subject as appreciated internationally by the participants.

The first session showed the way in which flow through combustors can be partially simulated observationally with kinetic models and by mathematical analysis. The general impression one gets is that there is still a long way to go before models can be really useful. The second session was largely reports of research in progress on relating physical and chemical parameters for the further elimination of unburnt hydrocarbon waste and ways of tackling NO (nitrous oxide) formations. At present water injection seems the best, but rather troublesome, method of suppressing these corrosive products by keeping the temperature below their formation level. However, from the third session, it appeared that such cooler gases can mean less than stoichiometric combustion-and, inevitably, unburnt hydrocarbon contaminants. The papers suggested, in fact, a temperature "slot" for combustion between $1,500-1,800 \mathrm{~K}$ in order to give the "purest" efflux. Control of visible smoke, the hydrocarbon and $\mathrm{CO}$ residue, is now being put into practice, beginning before ignition with vaporizing fuel injectors like those fitted in the latest Olympus in Concorde 02, which flew in January of this year.

In the fourth session, a paper on how 